\title{
Synthetic Studies Toward Bazzanin K: Regioselective and Chemoselective Three-Component Suzuki Coupling
}

\author{
Xuan Ju, Marshall Allen, Peng Zhao, Patrick Salvo, \\ Frank B. Dyer and Christopher M. Beaudry* \\ Department of Chemistry, Oregon State University, 153 Gilbert Hall, \\ Corvallis, OR 97331, United States \\ Email: christopher.beaudry@oregonstate.edu
}

\section{Supporting Information Table of Contents}

1. Depicted ${ }^{1} \mathrm{H}$ NMR and ${ }^{13} \mathrm{C}$ NMR Spectra S1-S16

2. ${ }^{1} \mathrm{H}$ NMR, ${ }^{13} \mathrm{C}$ NMR and 2D NOESY Spectra of 25a $\quad$ S17-S19

3. ${ }^{1} \mathrm{H}$ NMR, ${ }^{13} \mathrm{C}$ NMR and 2D NOESY Spectra of $\mathbf{2 5 b} \quad$ S20-S22

4. ${ }^{1} \mathrm{H}$ NMR and ${ }^{13} \mathrm{C}$ NMR Spectra of $\mathbf{1 3} \quad$ S23-S24 
Depicted ${ }^{1} \mathrm{H}$ NMR and ${ }^{13} \mathrm{C}$ NMR Spectra

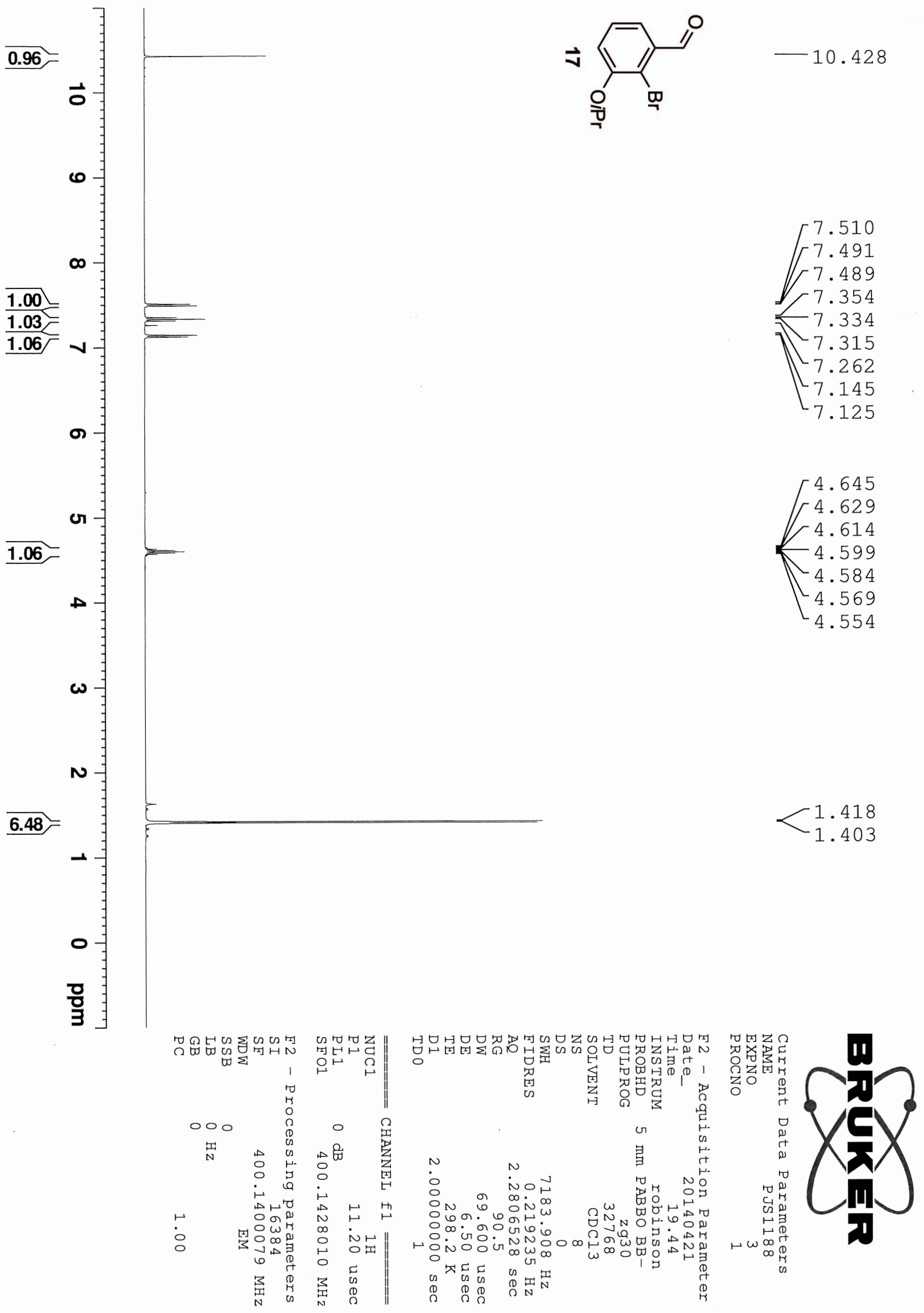




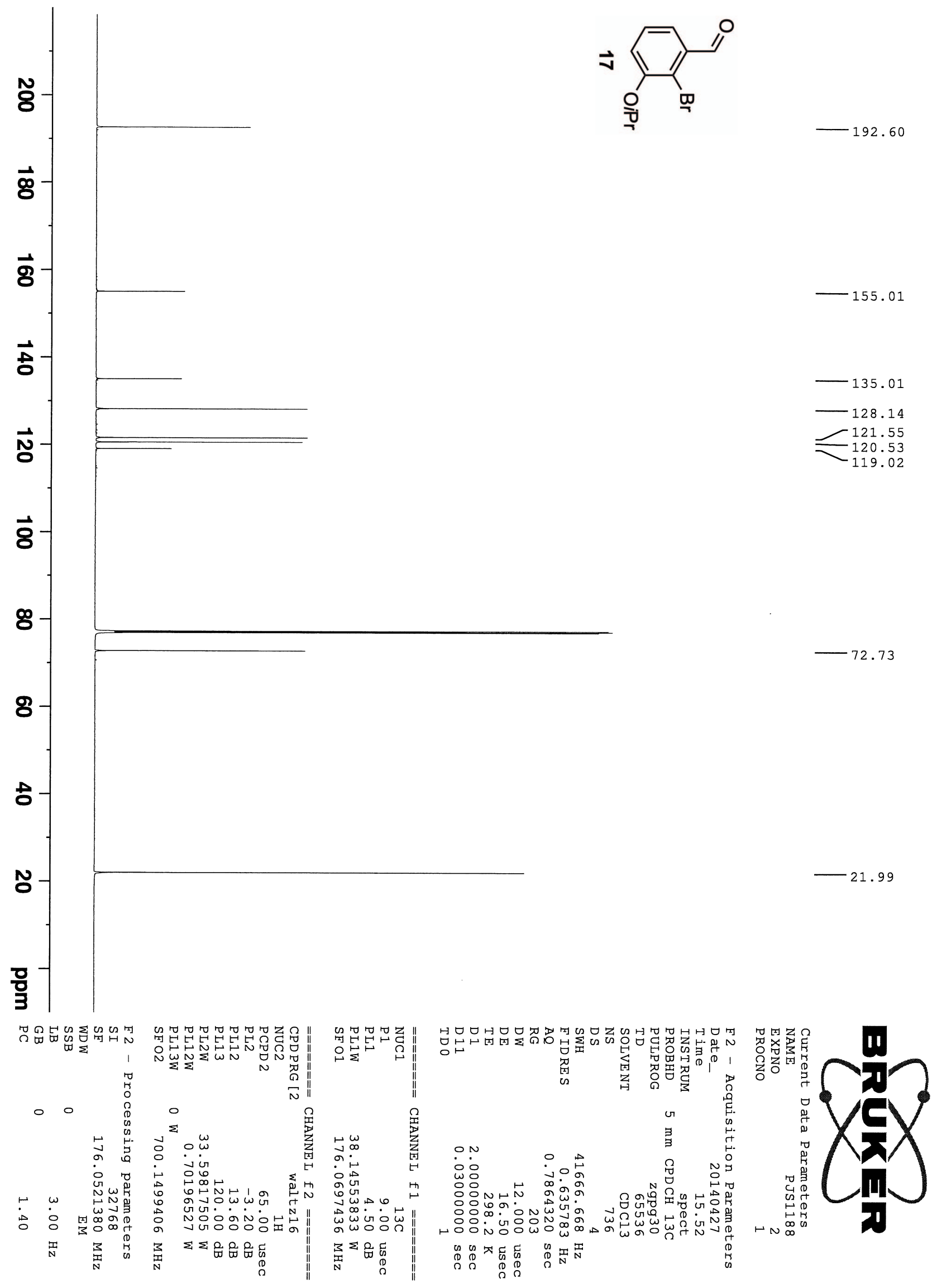




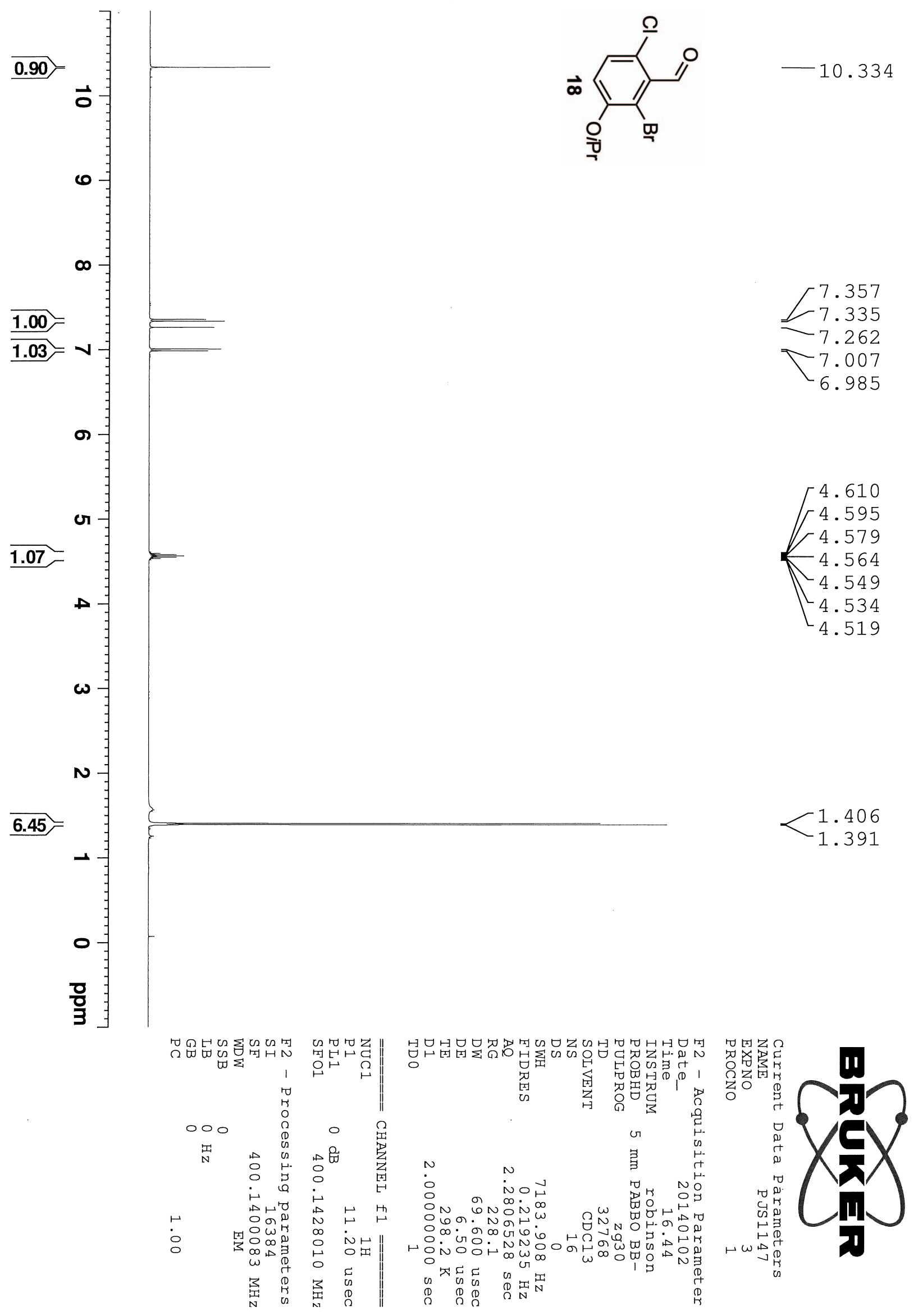




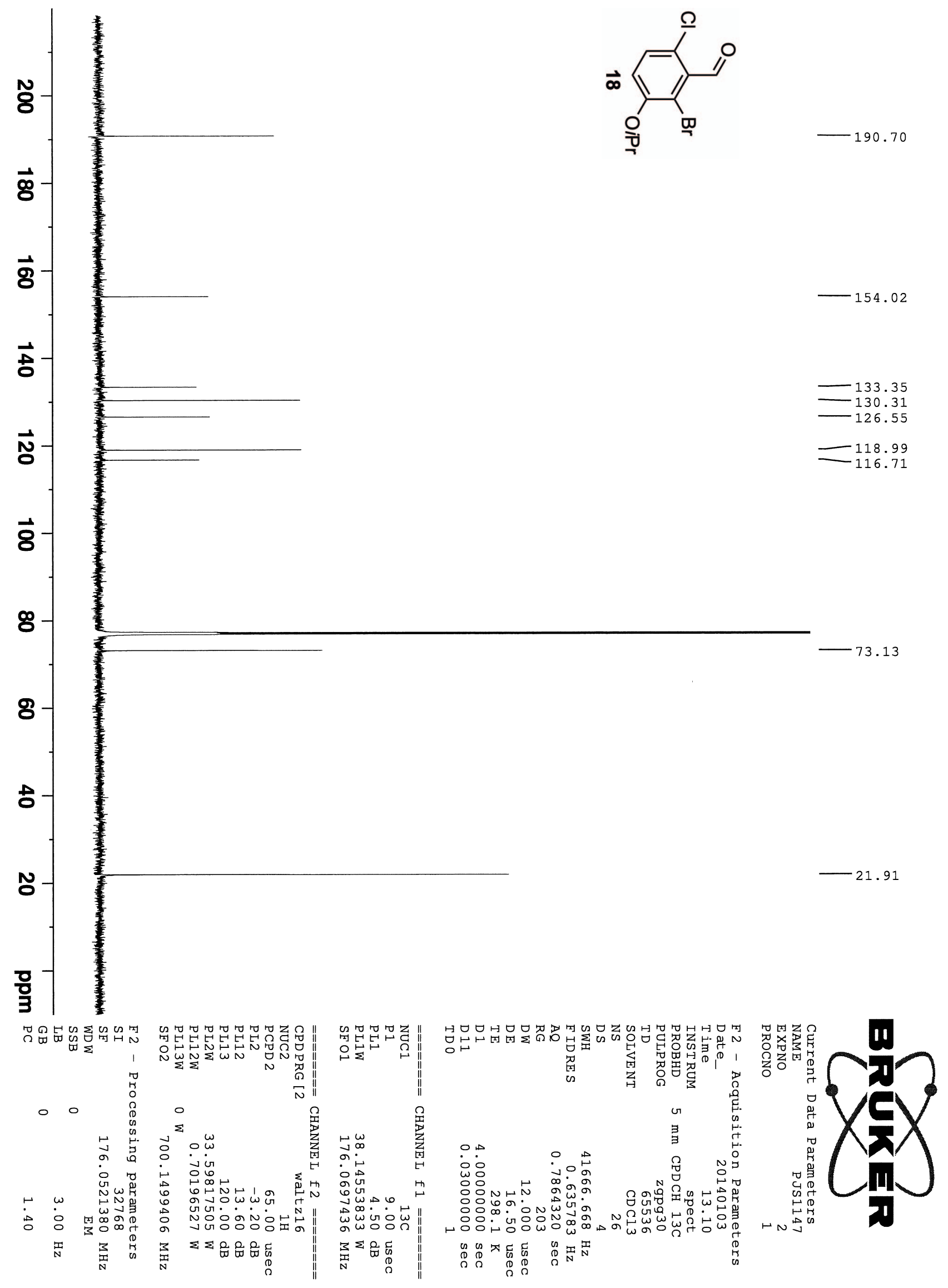




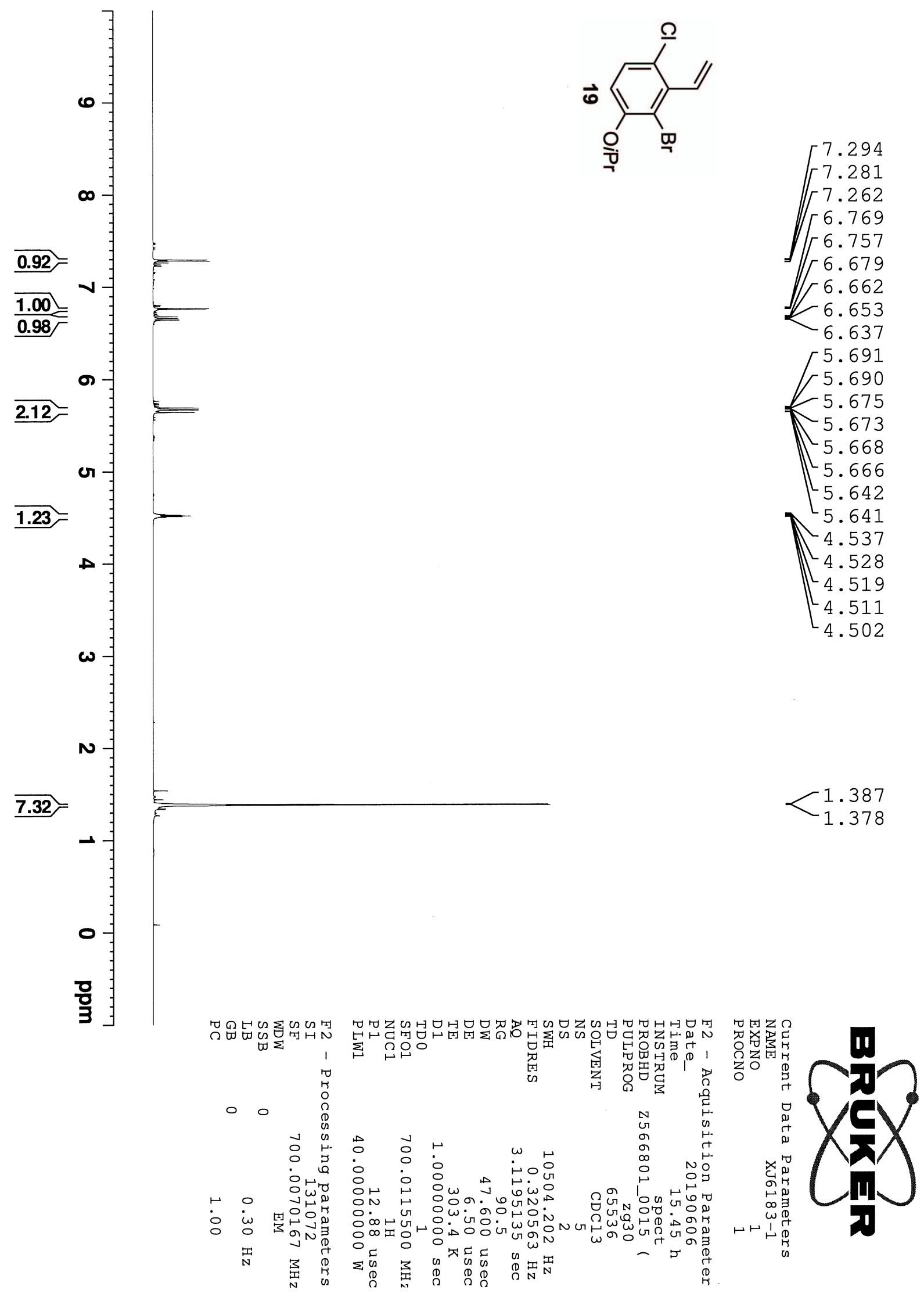




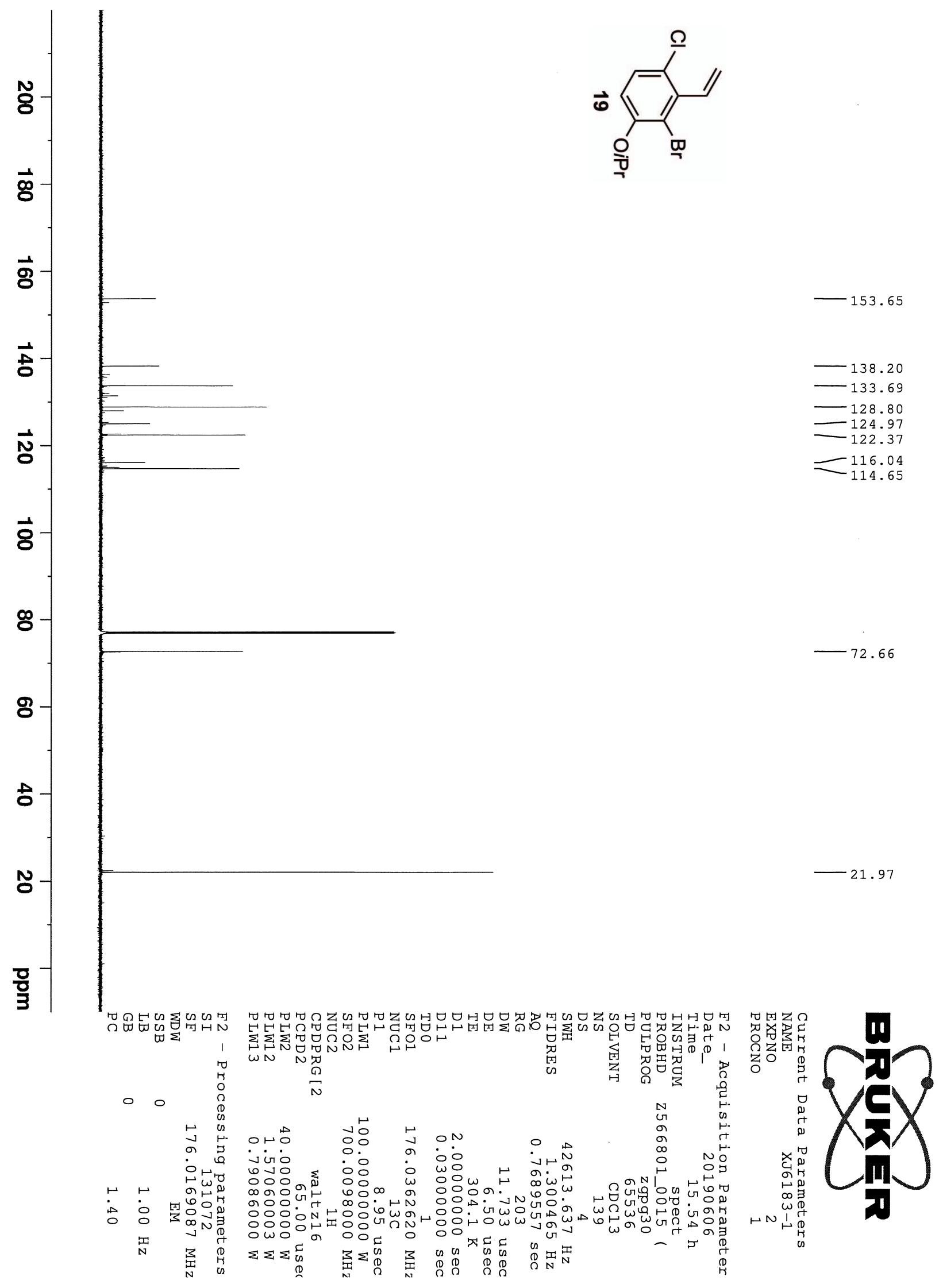




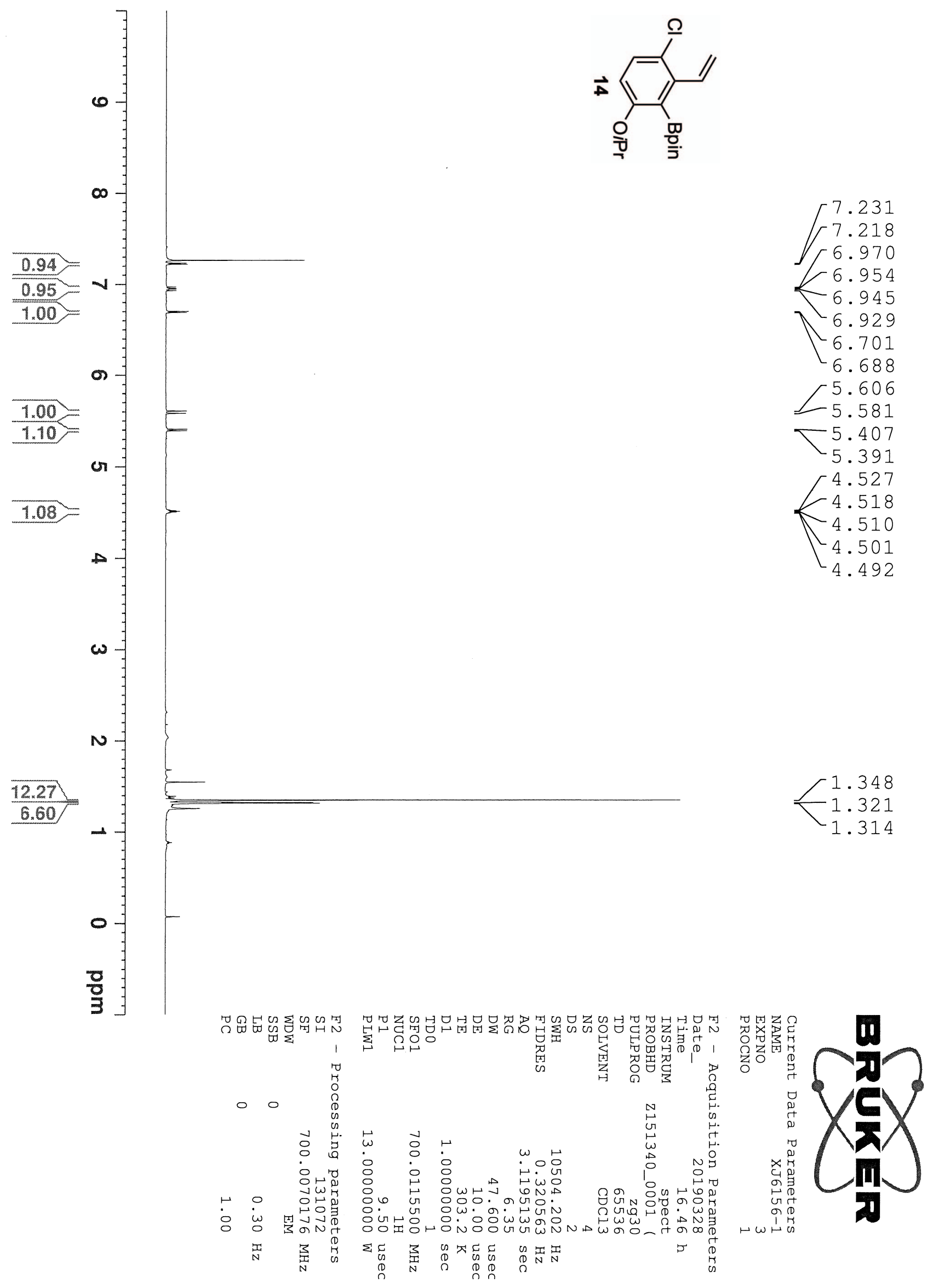




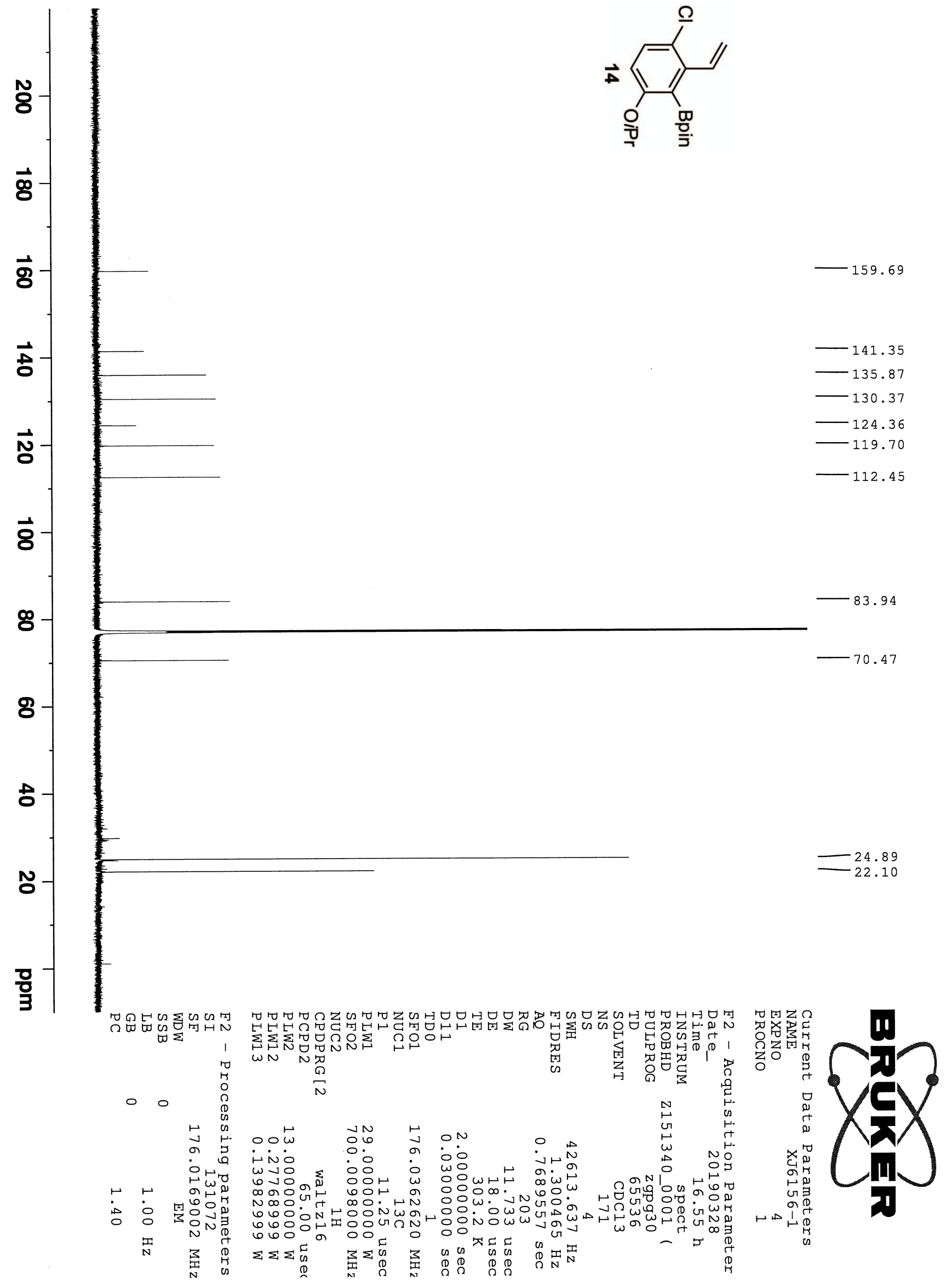




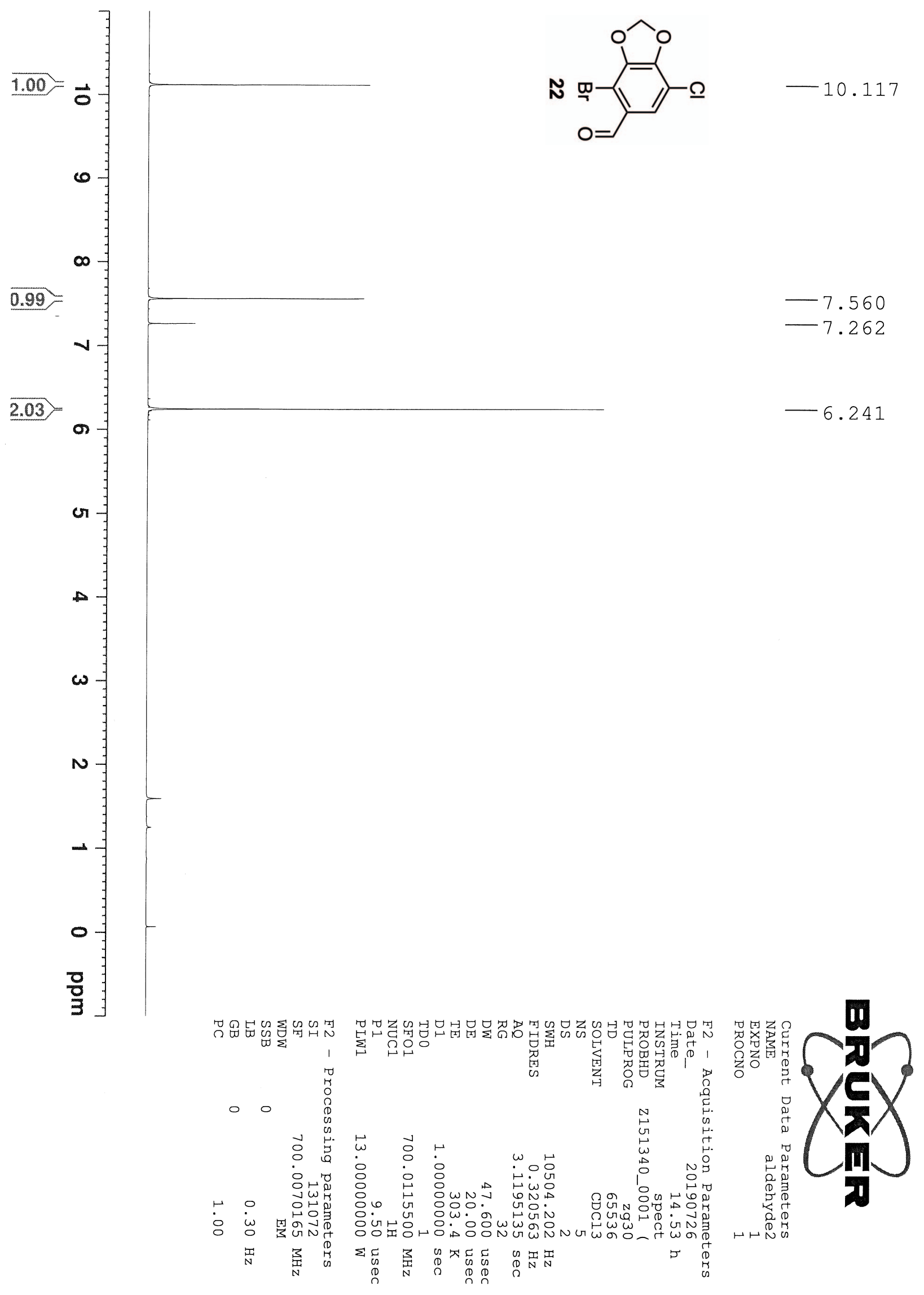




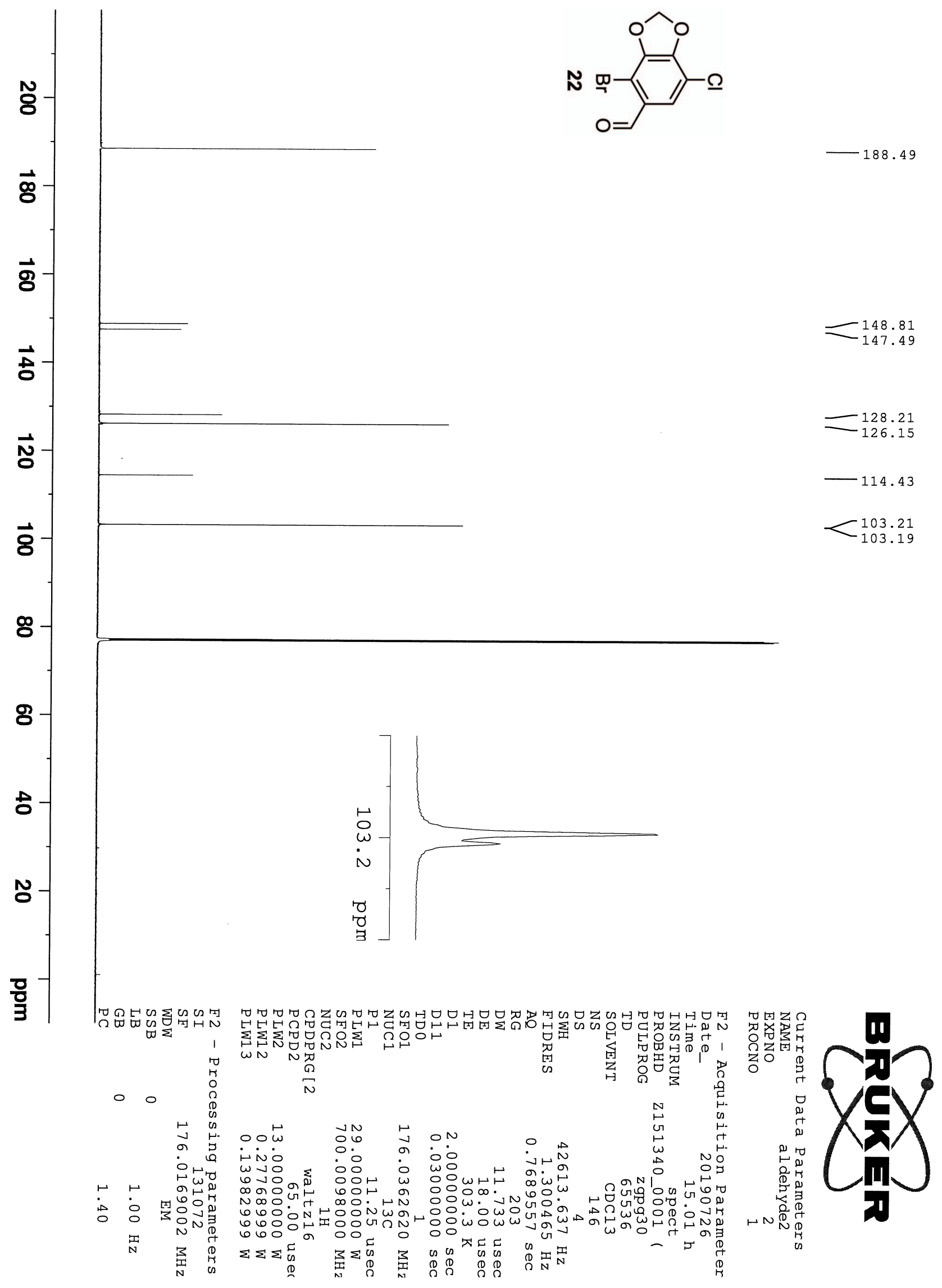




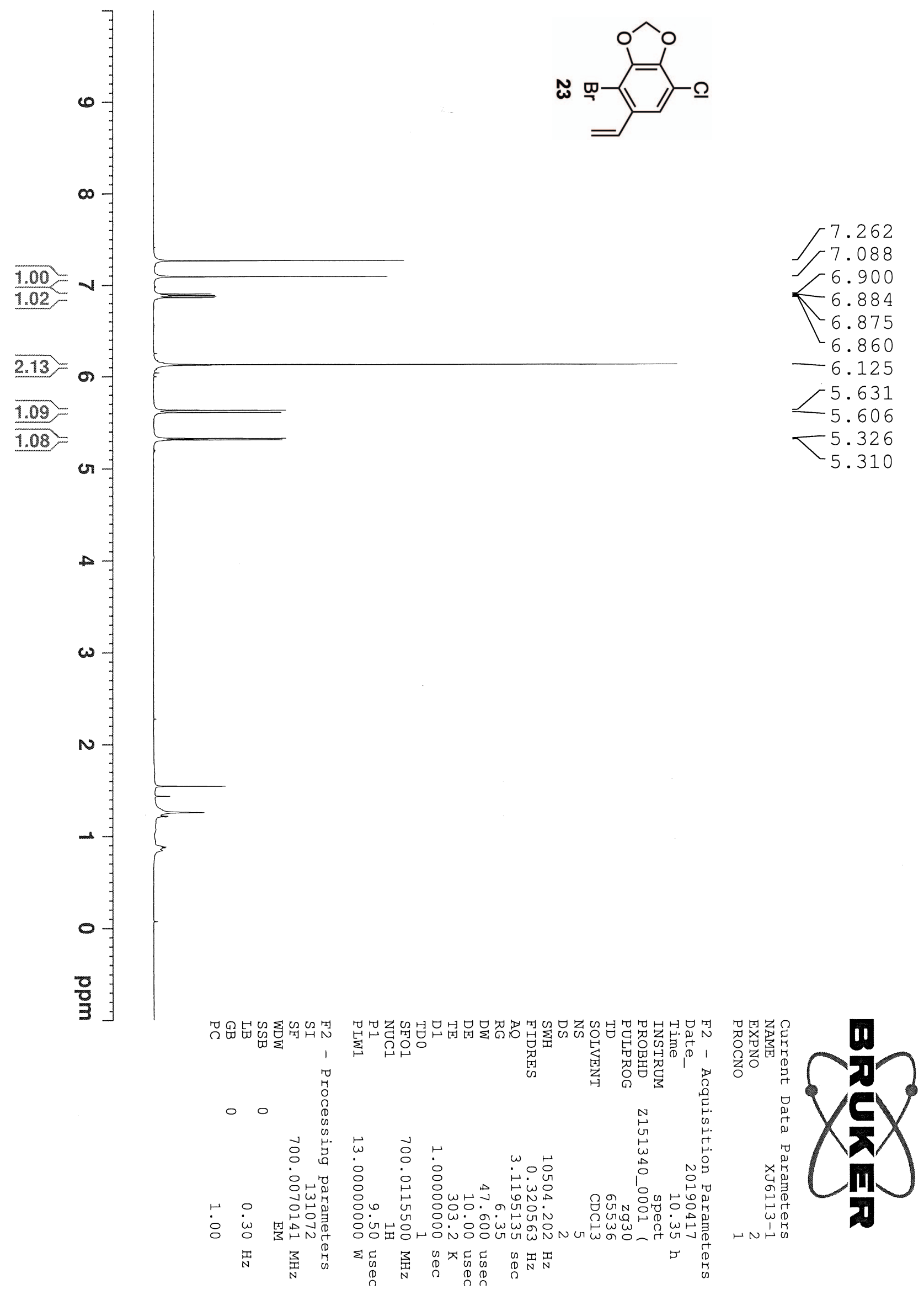




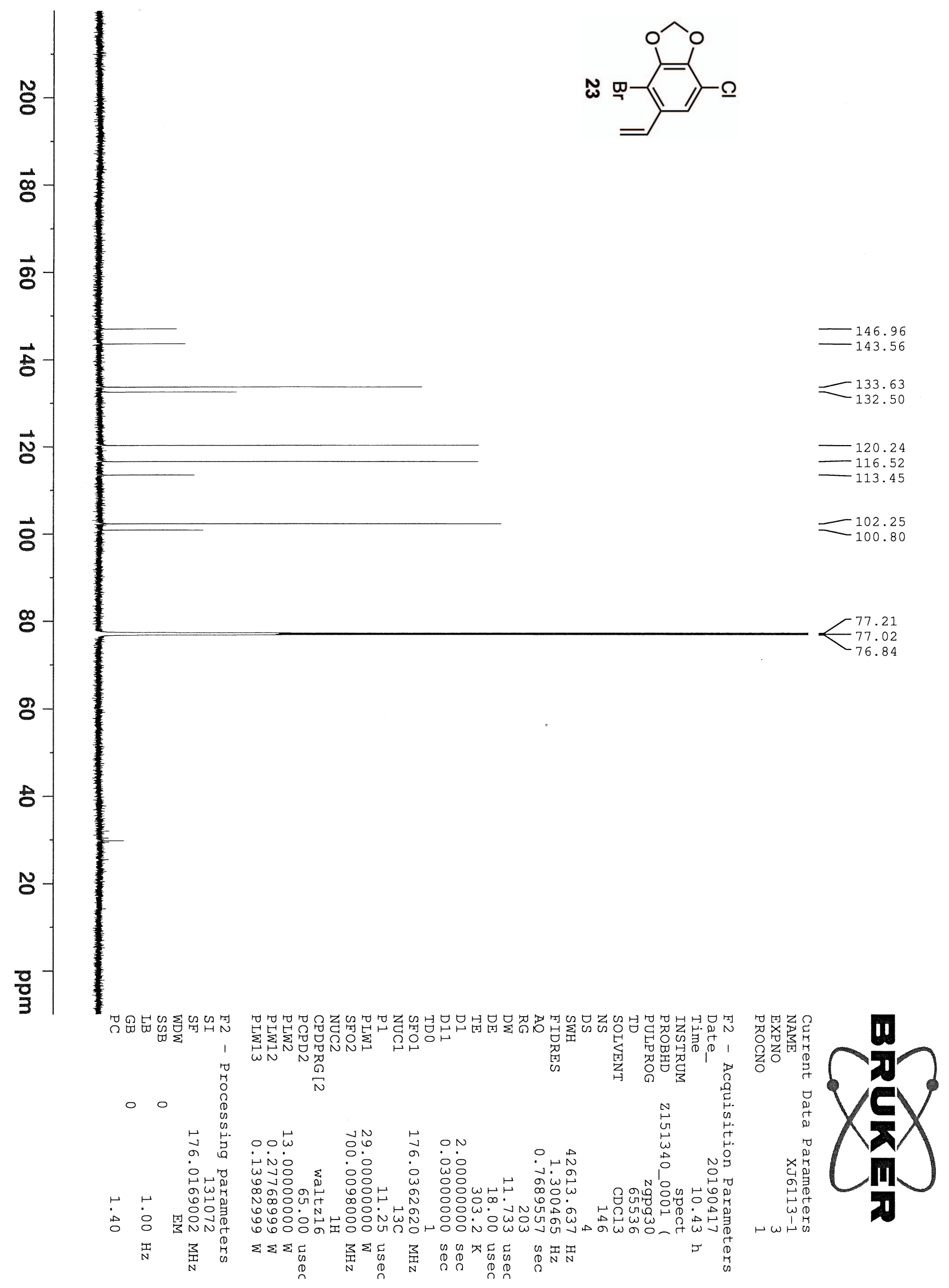




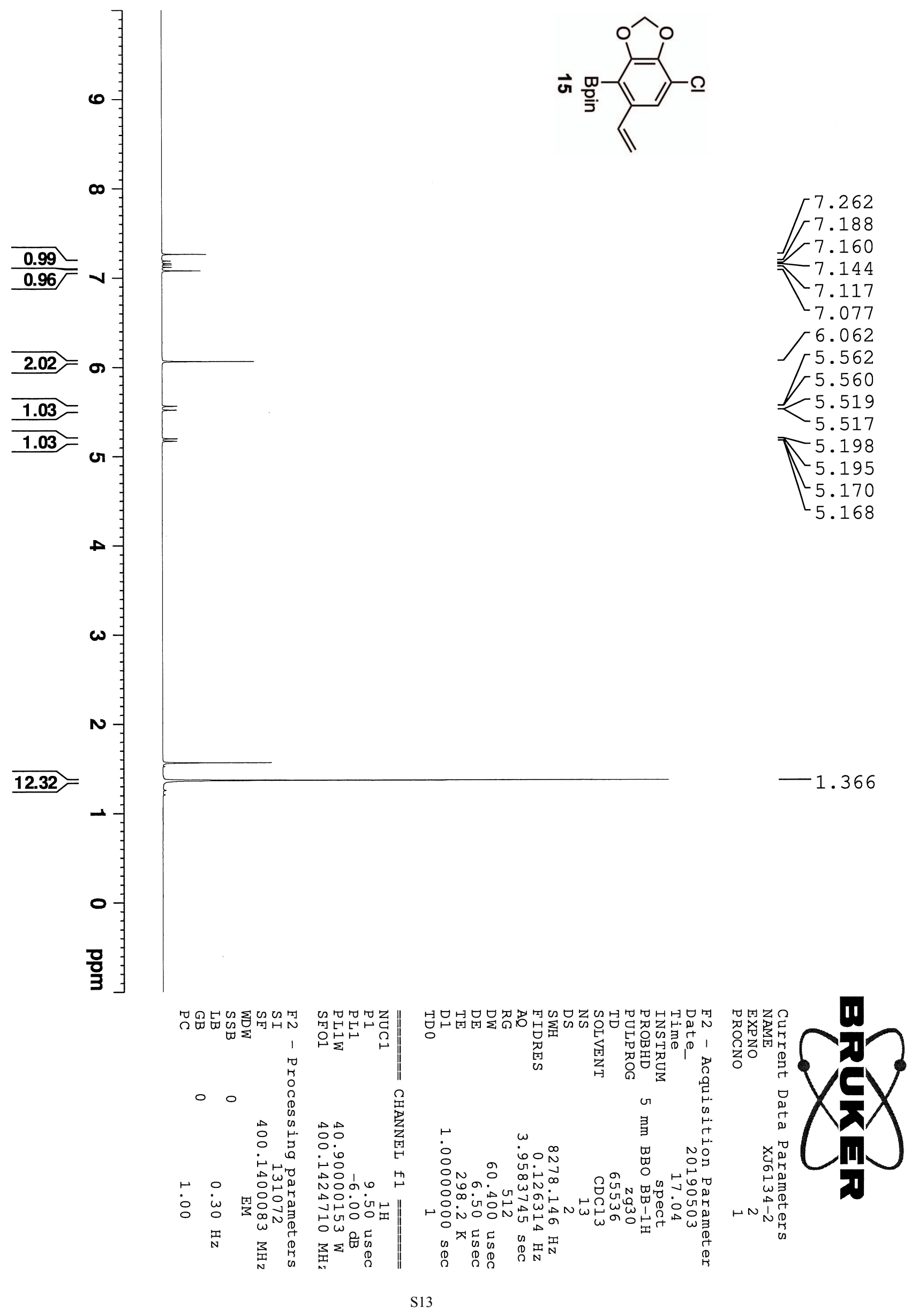




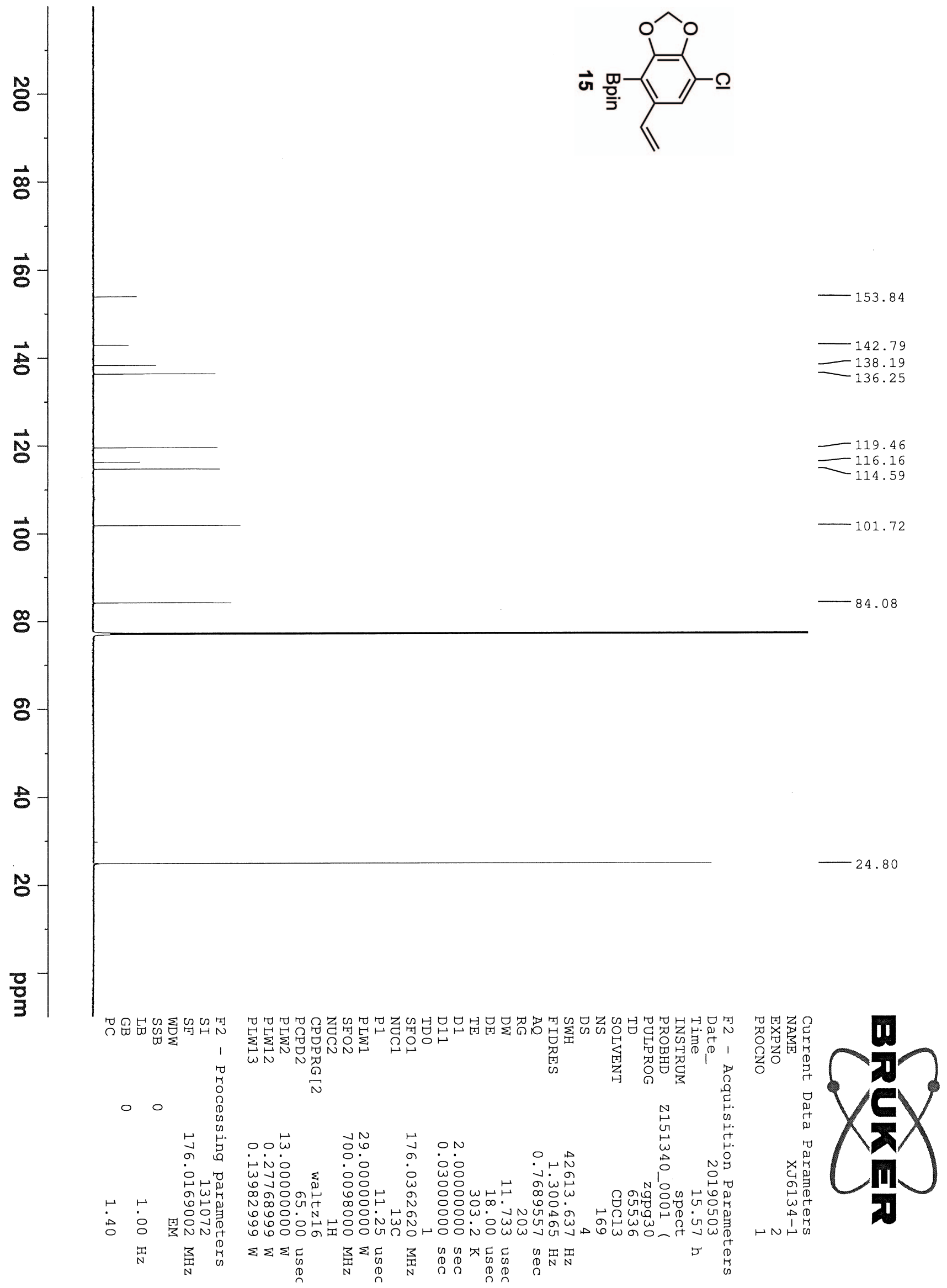




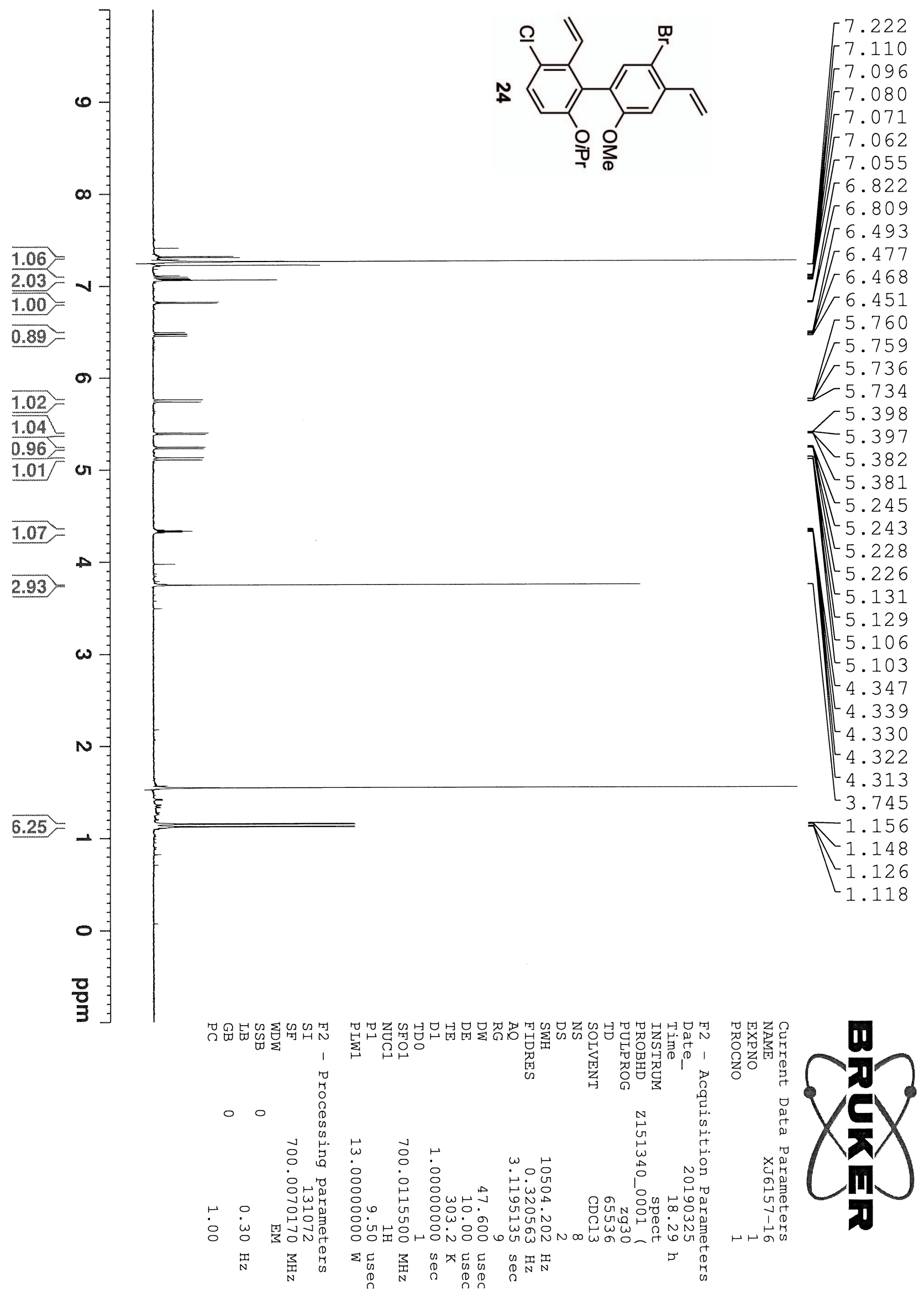




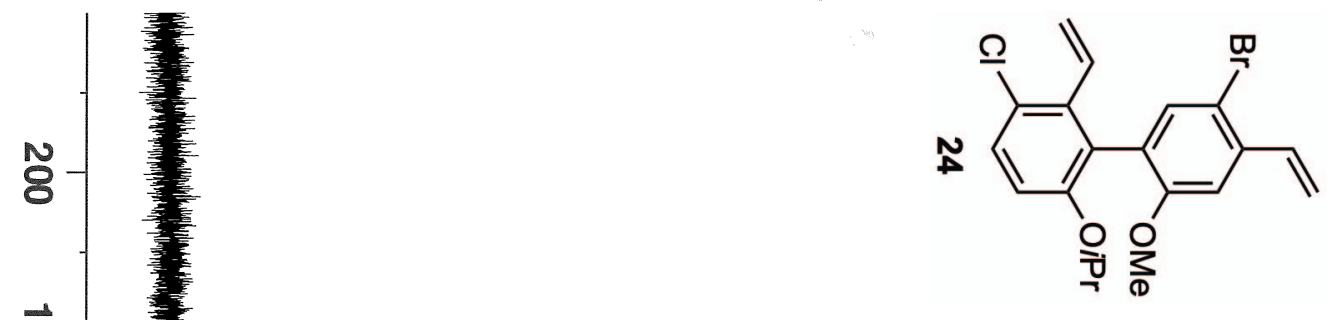

$\overrightarrow{8}$

$\overrightarrow{8}$

$\stackrel{\circ}{0}$

N

웅

\&

8

응

응

응
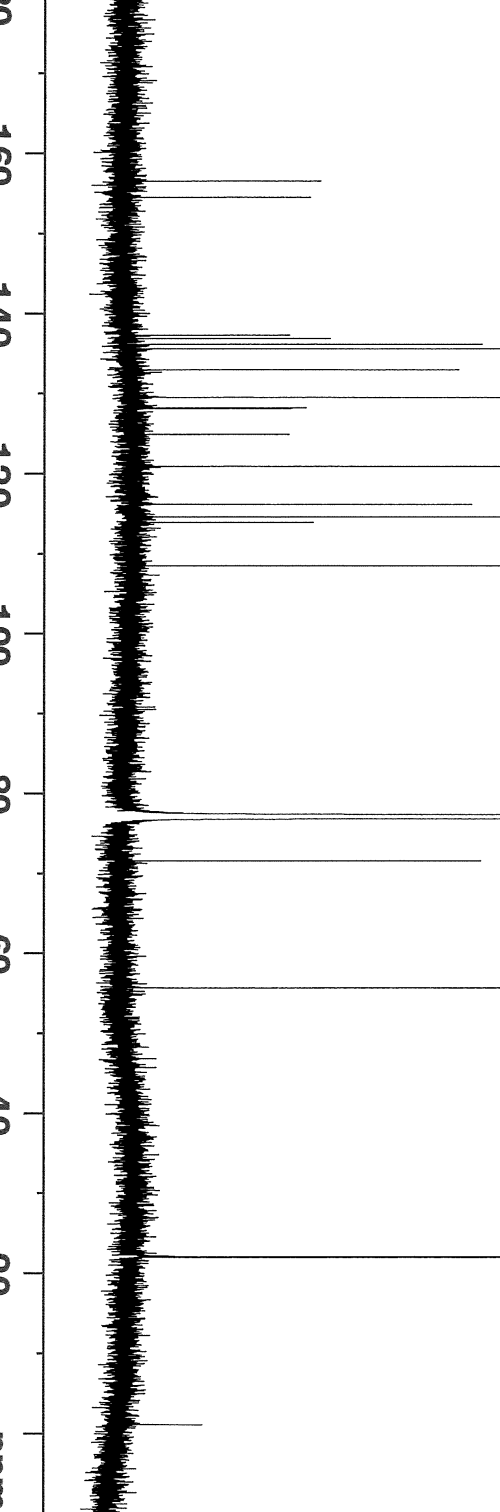

-

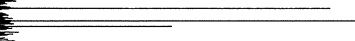

$-156.48$

$-154.45$

F 137.24

136.09

135.53

132.91

$-129.46$

128.16

124.84

$-120.84$

$-116.09$

114.55

113.83

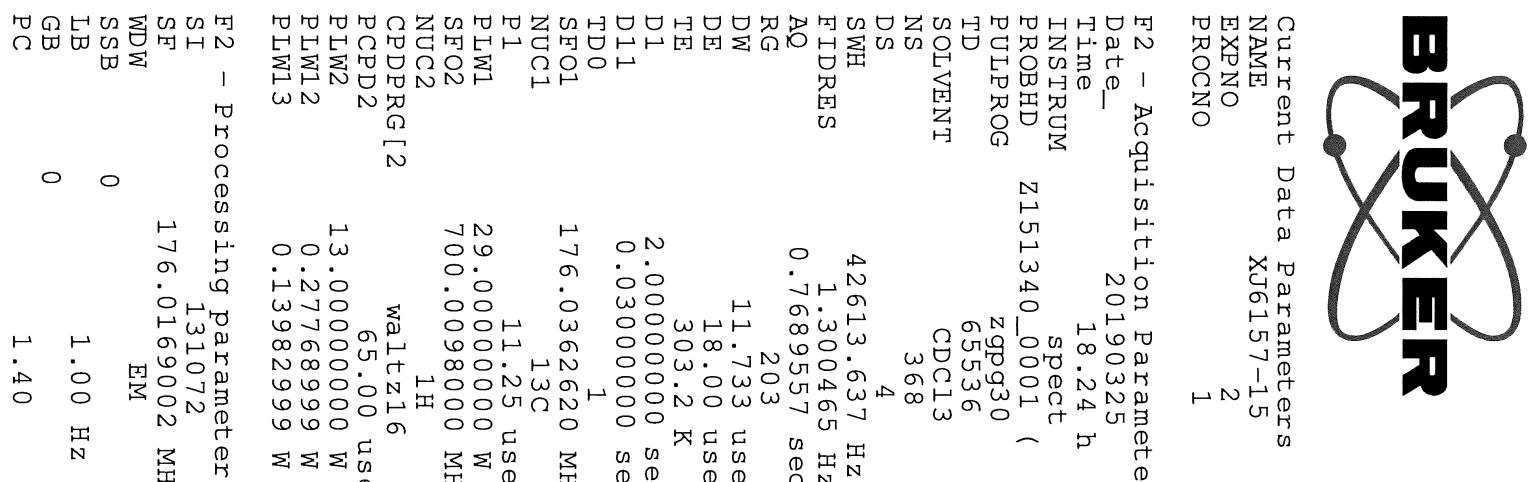




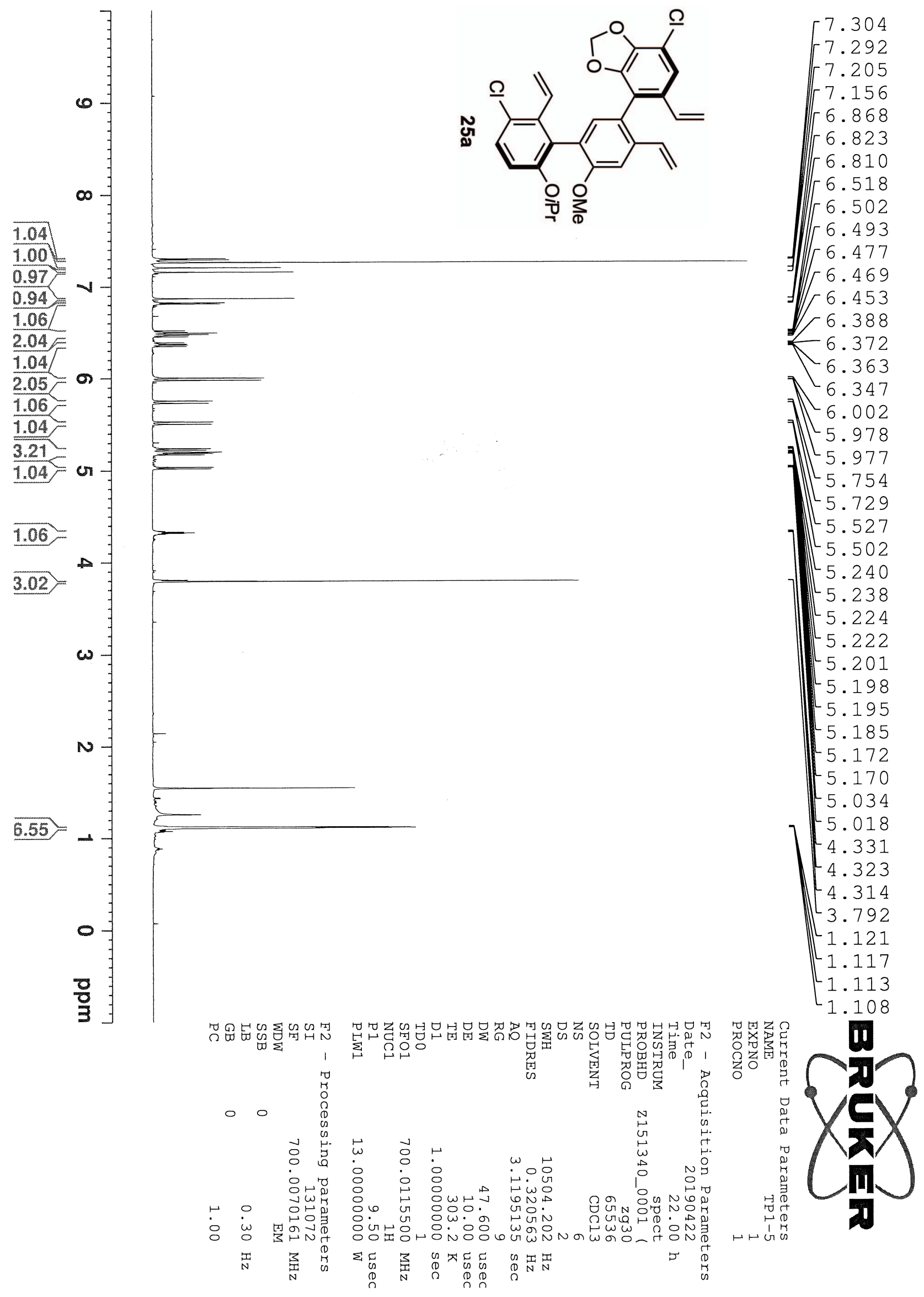



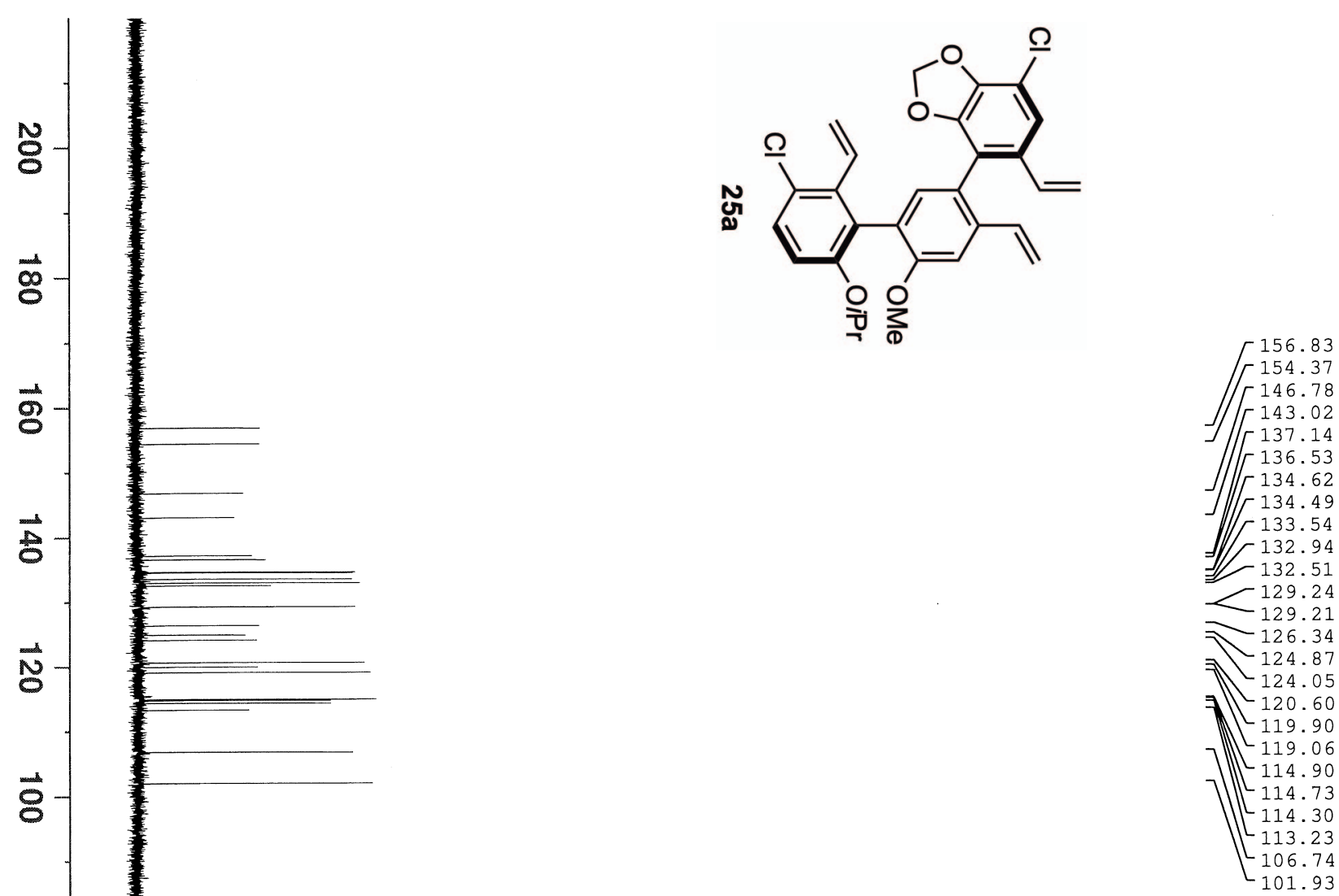

\&

용

하

ง

$\overrightarrow{8}$

$\overrightarrow{\vec{t}}$

$\overrightarrow{\widetilde{\nu}}$

$\overrightarrow{8}$

ø

。

ธ

믈

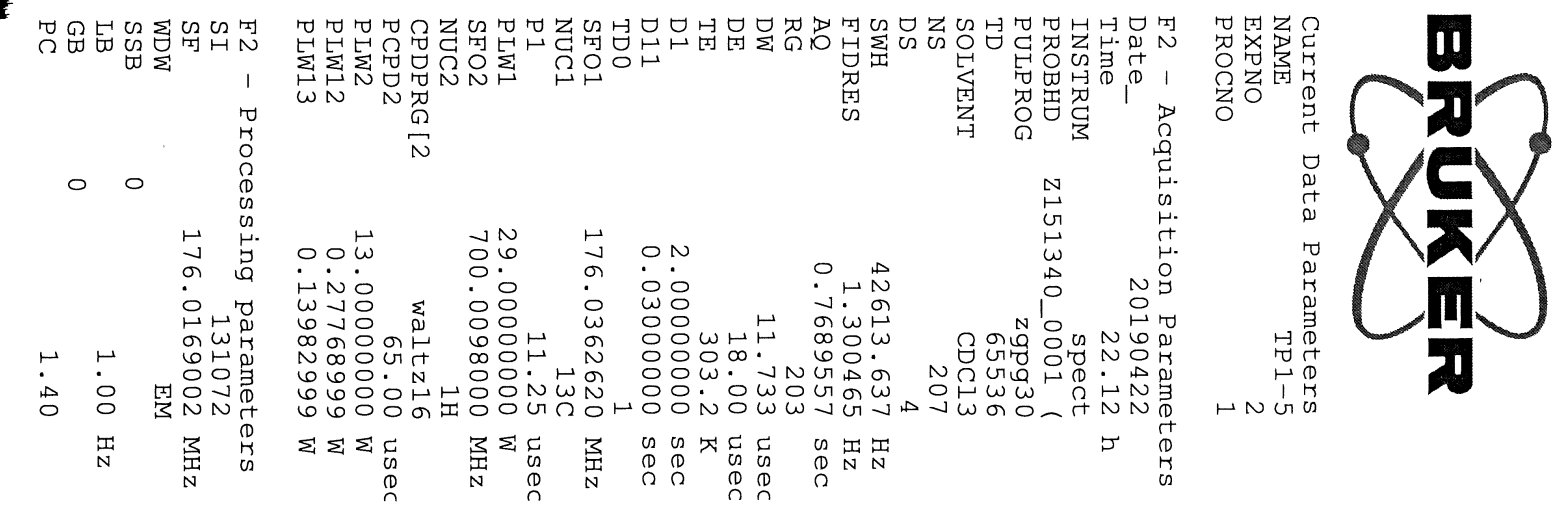




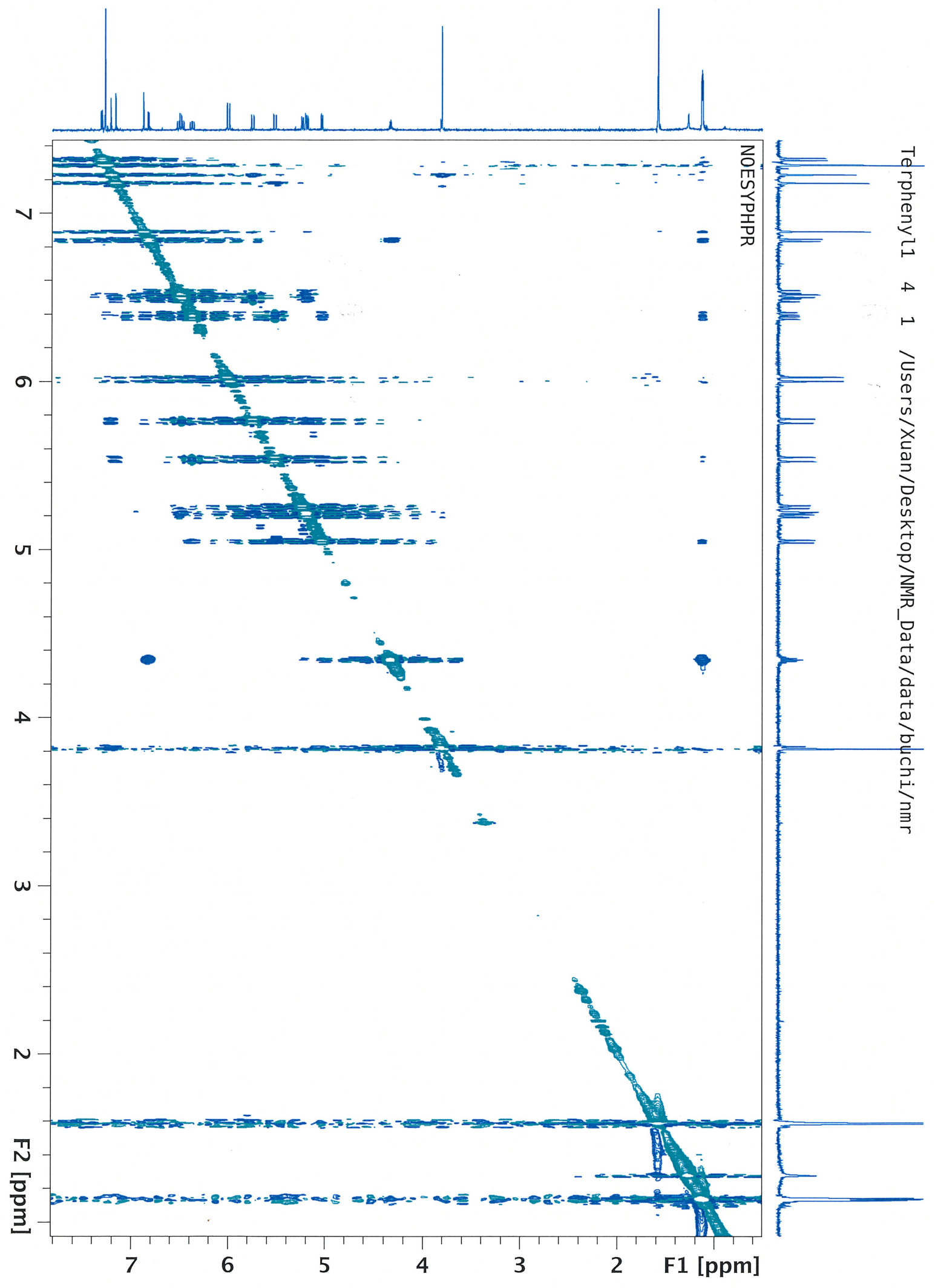




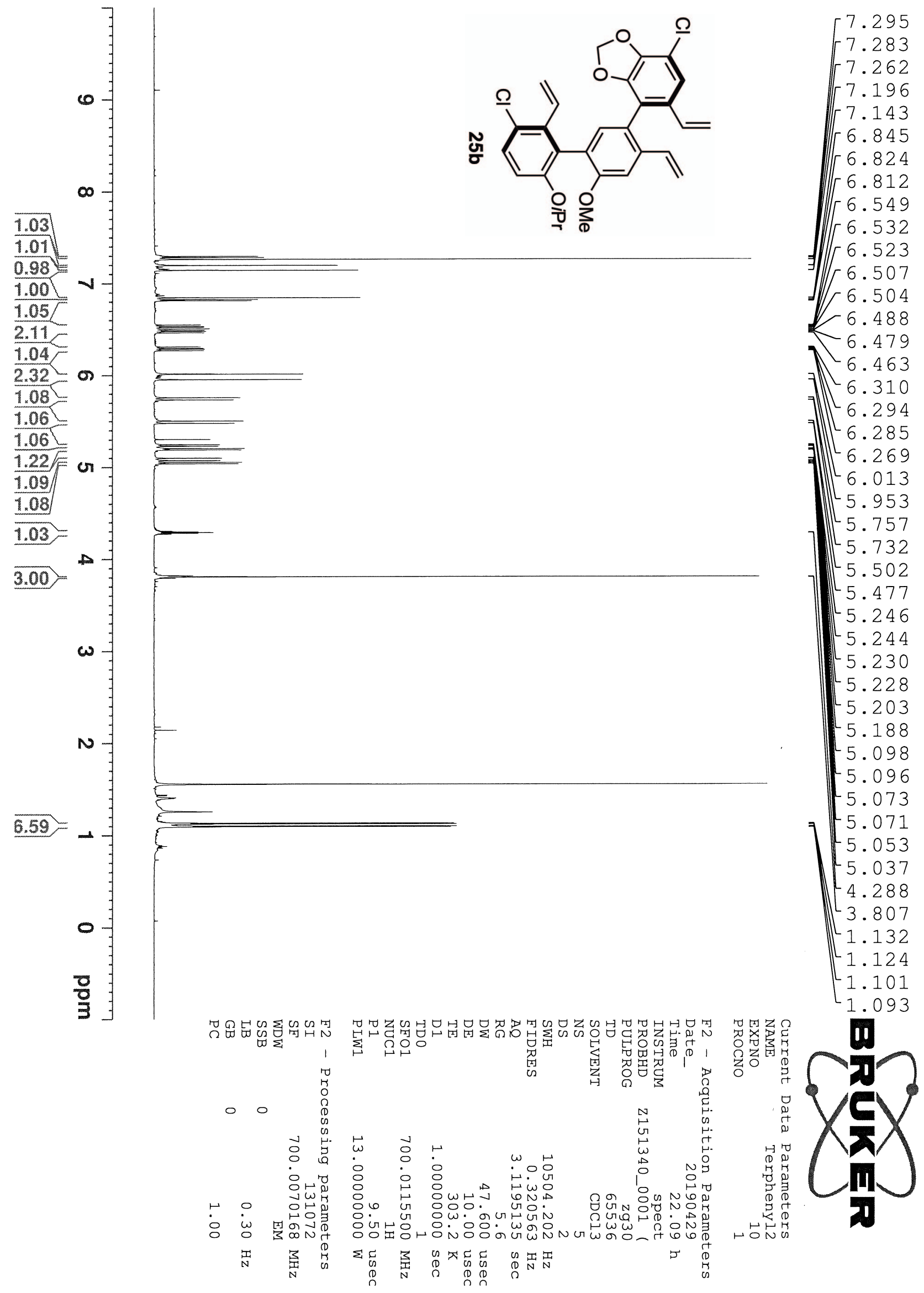




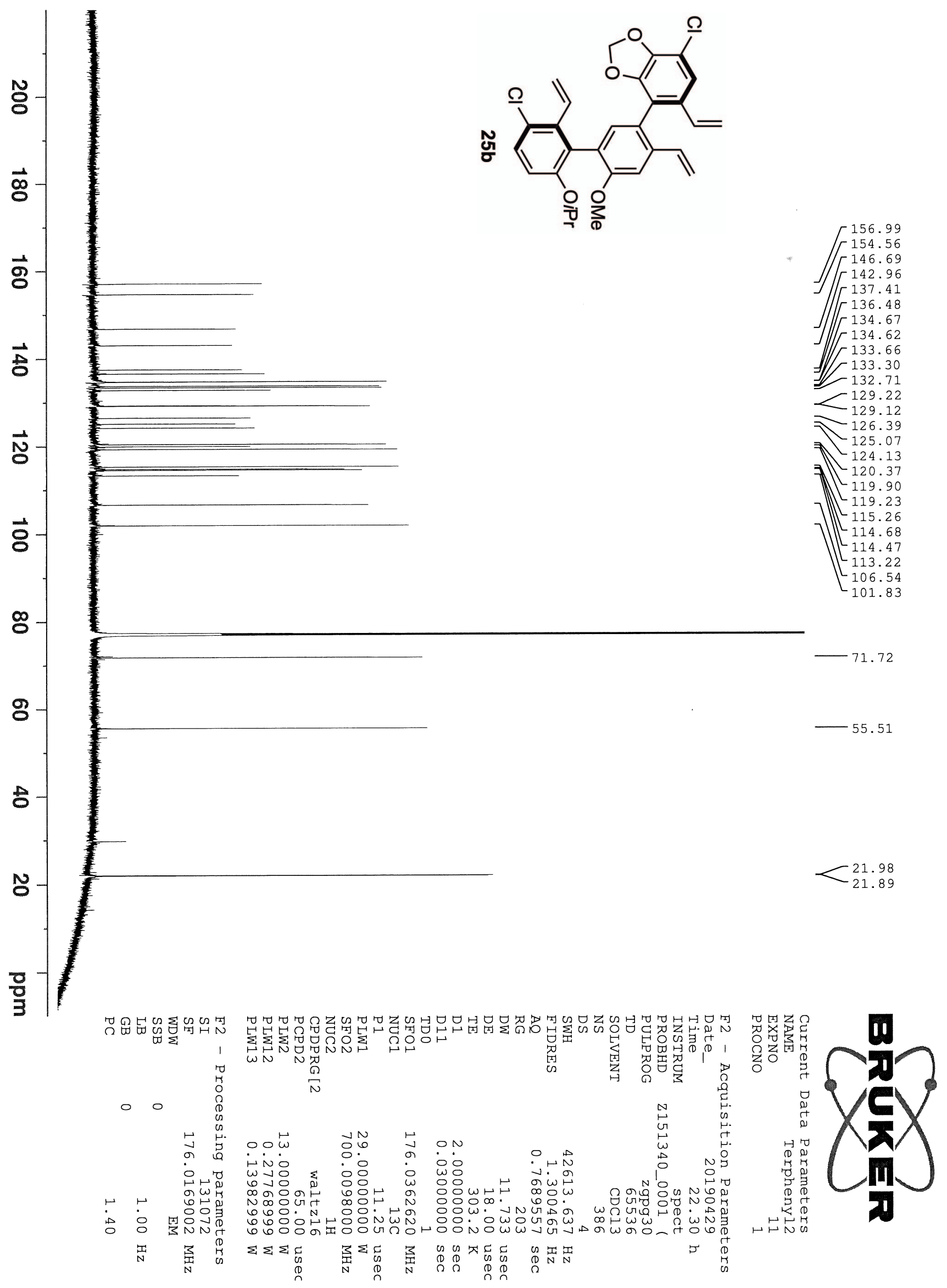


2D NOESY Spectra of $\mathbf{2 5 b}$

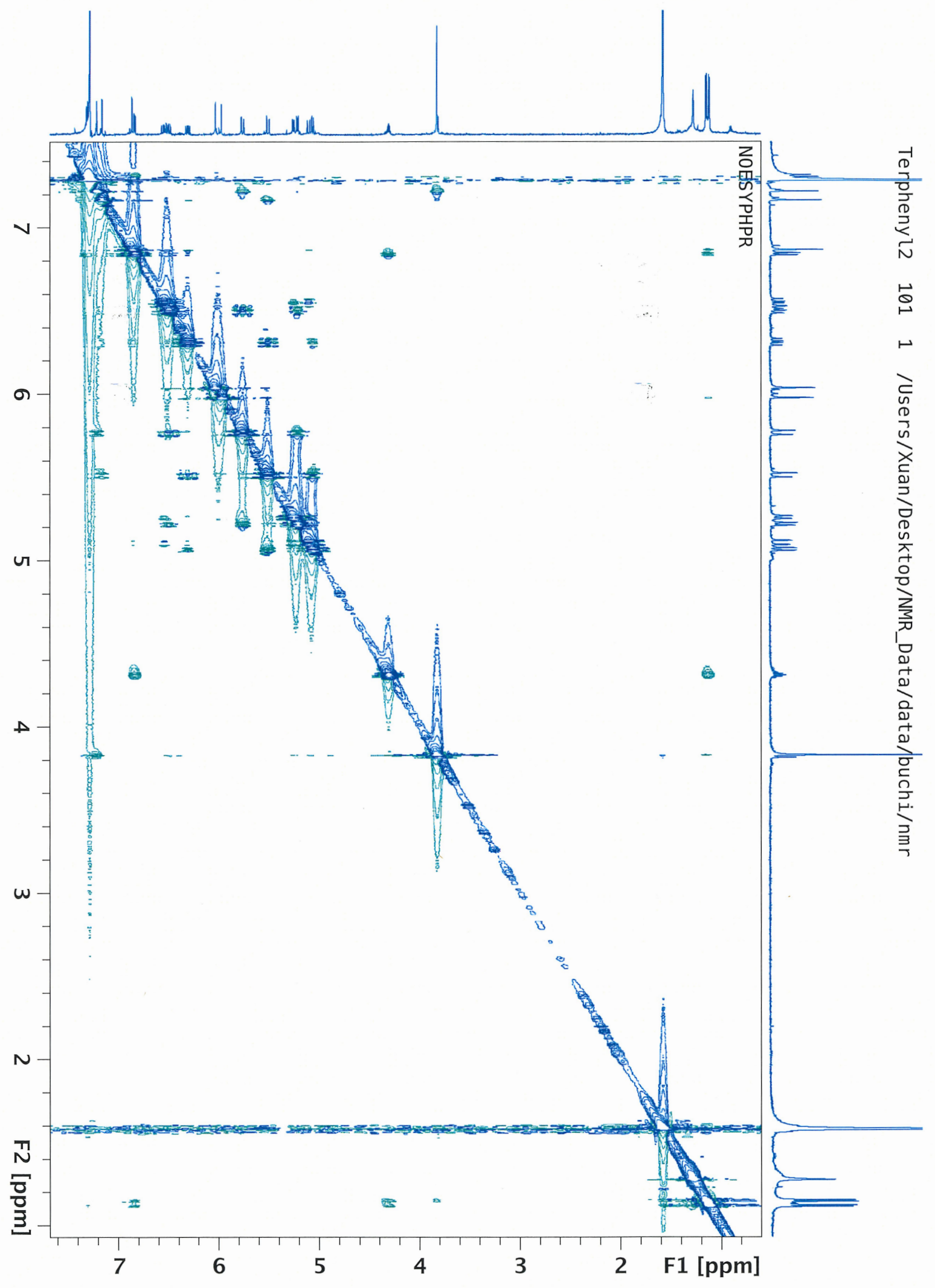




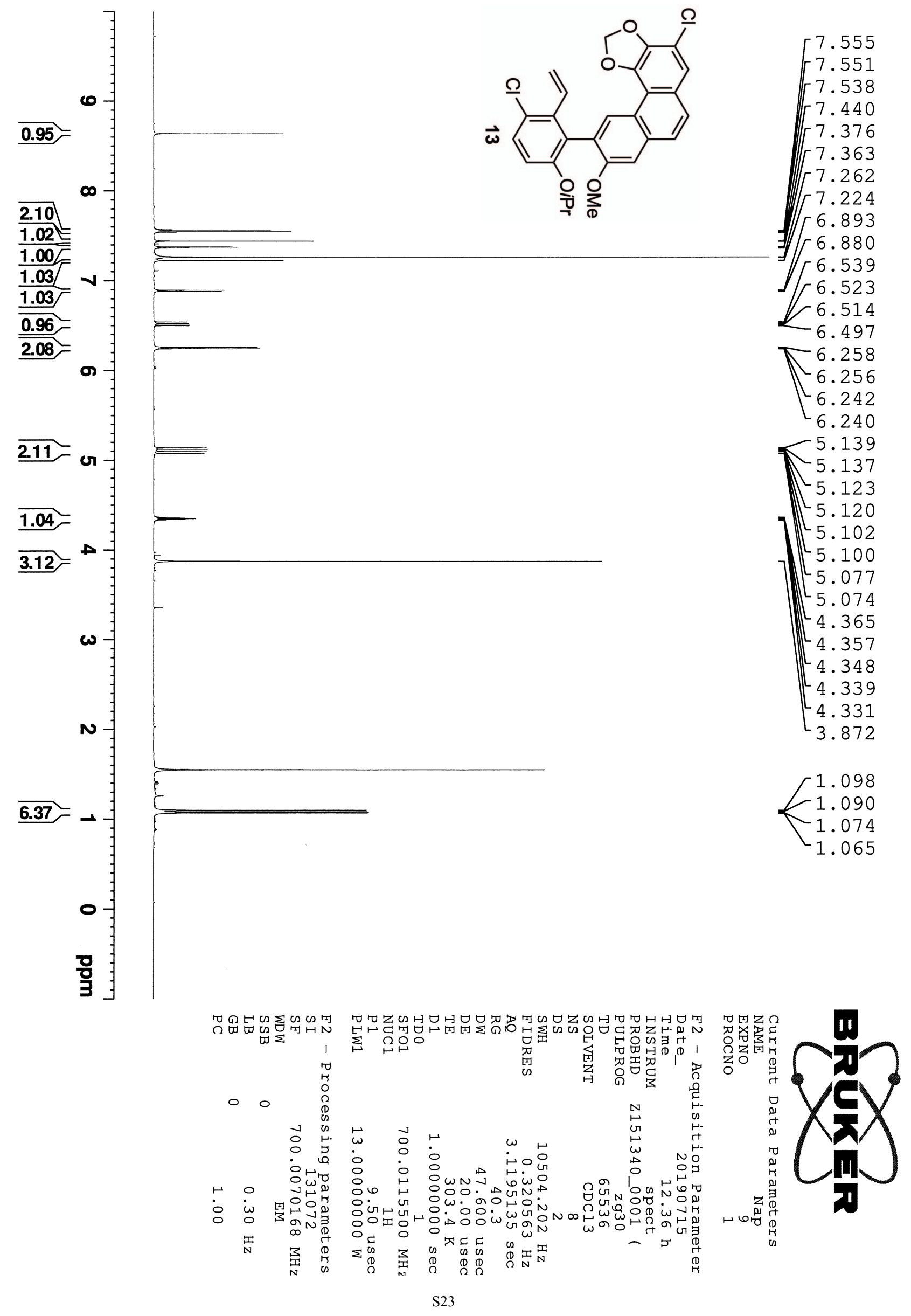




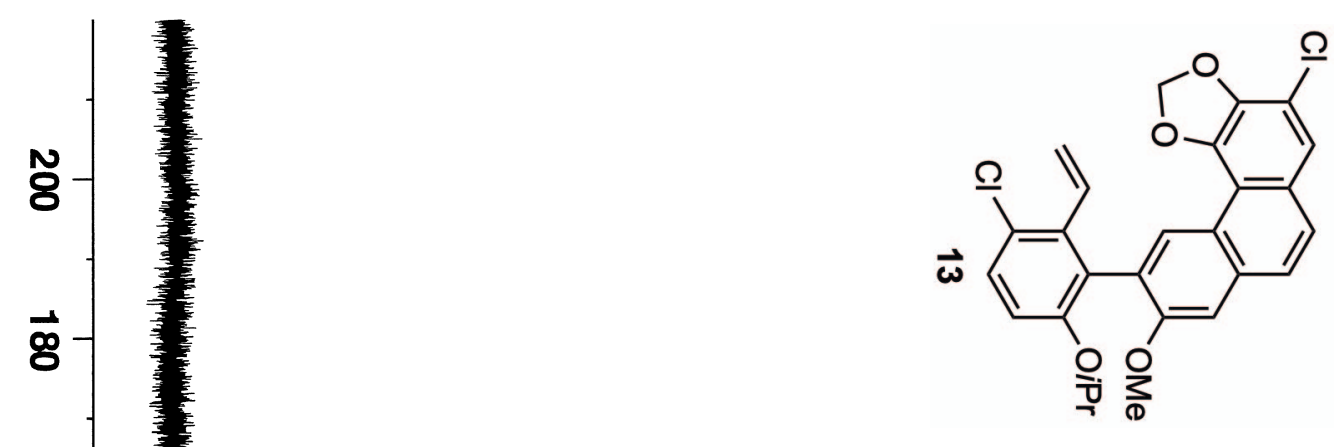

156.42

154.82
143.70

142.05

137.48

133.16

133.14

130.39

130.02

129.19

128.20

$-127.01$

$=126.31$

124.93

$7-121.58$

121.55

120.63

115.49

114.76

113.36

$\left[\begin{array}{l}107.09 \\ 101.97\end{array}\right.$

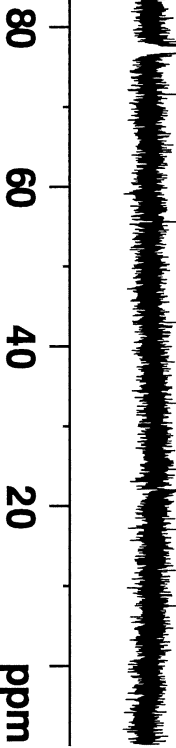

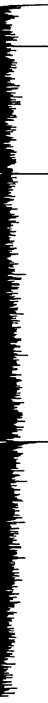

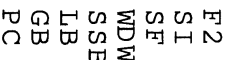

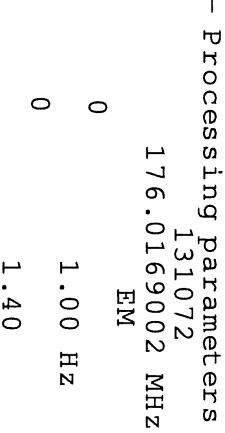

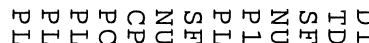

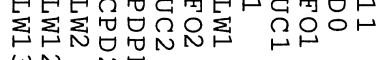
$\omega N N$ 